\section{Birlesik Dünya Arastrma Cypriot Journal of Educational \\ BD-CENTER \\ Sciences}

Innovasyon ve Yayıneılık Merkezi
Volume 17, Issue 2, (2022) 396-409

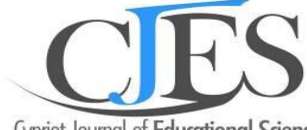

Cypriot Journal of Educational Sciences

\title{
The effect of productive failure in a digital inquiry environment on developing deep understanding and achievement of organic chemistry among secondary school students
}

\author{
Sahar Mohammed Yousef Ezzeldin, ${ }^{* 1}$ Prince Sattam Bin Abdulaziz University, College of Education, \\ Department of Educational Sciences, Wadi Addwaser, Saudi Arabia / Benha University, Egypt \\ https://orcid.org/0000-0001-7644-6875
}

\section{Suggested Citation:}

Ezzeldin, S. M. Y. (2022). The effect of productive failure in a digital inquiry environment on developing deep understanding and achievement of organic chemistry among secondary school students. Cypriot Journal of Educational Science. 17(2), 396-409 https://doi.org/10.18844/cjes.v17i2.6822

Received from November 10, 2021; revised from December 24, 2021, accepted from February 22, 2022

${ }^{\circ} 2022$ Birlesik Dunya Yenilik Arastirma ve Yayincilik Merkezi. All rights reserved.

\section{Abstract}

This study measures the effect of productive failure instruction in a digital inquiry environment on developing deep understanding and achievement of organic chemistry among Saudi Arabian secondary school students. The study adopted the experimental design of control and experimental groups with pre- and post-measurements. The sample comprised 66 secondary school students from Wadi Al-Dawasir Governorate, Riyadh, Saudi Arabia, distributed into the experimental group ( $n=32)$ and the control group $(n=34)$. The data collection utilised the deep understanding test and the achievement test of organic chemistry. The results revealed that there were statistically significant differences at $\alpha=0.05$ between the means of the scores of the experimental and control groups in the deep understanding level and the achievement test of organic chemistry in favour of the experimental group. Recommendations and suggestions are also presented in light of the study results.

Keywords: Productive failure, digital inquiry environment, deep understanding of organic chemistry, the achievement of organic chemistry.

\footnotetext{
* ADDRESS OF CORRESPONDENCE: Sahar M. Y. Ezzeldin, Prince Sattam Bin Abdulaziz University, College of Education, Department of Educational Sciences, Akharag, Saudi Arabia / Benha University, Egypt Postal Code: 111111

E-mail address: s.ezzeldin@psau.edu.sa / Tel +966501799330
} 
Ezzeldin, S. M. Y. (2022). The effect of productive failure in a digital inquiry environment on developing deep understanding and achievement of organic chemistry among secondary school students. Cypriot Journal of Educational Science. 17(2), 396-409

https://doi.org/10.18844/cjes.v17i2.6822

\section{Introduction}

Thinking is one of the most important educational goals. Consequently, greater attention must be paid to its development through shifting away from the traditional teaching and learning approach that focuses on rote and unidirectional learning and moving from the surface level to the deep level of knowledge. In response, McFarland and Moulds (2007) asserted that deep understanding is a primary goal in science education that can be achieved through four conditions: generative knowledge, various activities, continuous evaluation and clear goals.

Chemistry is one of the basic sciences that has a role in all phenomena surrounding human beings and one of the most significant branches that changes human life and contributes to its development. Therefore, it requires greater attention from the teacher to achieve the student's deep understanding and provide a supportive educational environment that increases his achievement level.

The International Association for the Evaluation of Educational Achievement (2015) points out that the increasing achievement level in science and mathematics is through learning how to 'fail well' or being flexible in facing obstacles, which is known as a productive failure (PF). In the literature, the concept of PF refers to a pattern of directive discovery learning or the highest form of investigation.

Incorporating new technologies provides sufficient incentive for students to practice learning without feeling frustrated, even while utilising PF activities (Dickson et al., 2020). Hence, the digital learning environment can be designed using PF to practice the inquiry process effectively (Kennedy-Clark, 2009). The literature supports the effectiveness of using cognitive failure in the e-learning environment (Dickson et al., 2020; Kennedy-Clark, 2009; Kapur, 2010; Song, 2018). Studies also focus on the efficient impact of using PF with inquiry learning and provide procedures for combining them (Brand et al., 2019; Arrington \& Xu,Arrington \& Xu, 2019; Kapur \& Bielaczyc, 2012; Toh \& Kapur, 2017).

According to the above-mentioned description, it is necessary to develop a deep understanding of learning chemistry, and PF - in this condition - can prepare students' minds to better understand new concepts deeply. Therefore, the current study sought to measure the effect of PF instruction in a digital inquiry environment on developing a deep understanding and achievement of organic chemistry among Saudi Arabian secondary school students.

\section{Literature review}

\subsection{PF and digital inquiry environment}

PF refers to an educational strategy that requires learners to struggle while trying to find solutions to problems around a specific concept before direct instruction. Studies revealed that this strategy prepares students for future learning and for the process of transferring the knowledge they have acquired from one discipline to another (Kennedy-Clark, 2009; Steenhof et al., 2019).

The PF idea stems from the perception that there are four outcomes associated with the educational activity: PF, productive success, non-PF and non-productive success. Failure or success here indicates the short term of the learner's initial performance (Kapur, 2015). In this method, there is no direct instruction on how to solve the problem as problems are open and have many paths and solutions (Loibl \& Leuders, 2019). Such problems are poorly structured, but they are not frustrated as they suit the learners' capabilities (Kapur, 2010; Kapur \& Bielaczyc, 2012).

The poorly and well-constructed problems differ in three essential elements, which are the amount of available information about the situation (the current state of the problem); the degree of clarity of the goals to be achieved (the desired state); and the amount of knowledge about the means that can help in 
Ezzeldin, S. M. Y. (2022). The effect of productive failure in a digital inquiry environment on developing deep understanding and achievement of organic chemistry among secondary school students. Cypriot Journal of Educational Science. 17(2), 396-409

https://doi.org/10.18844/cjes.v17i2.6822

bringing about the requisite change in the current situation to achieve the desired goals (Sternberg, 1999).

Solving complex problems in a multi-user virtual learning environment helps learners to understand the fundamental stages of PF. It supports learners to focus on the initial cycle of addressing PF to develop a series of design considerations that teachers can implement in a rich learning environment. In addition, it helps learners develop strategies for dealing with complex problems across various spheres of knowledge (Kennedy-Clark, 2009). Chowrira et al. (2019) demonstrated that PF is a potential method that encourages meaningful learning through solving challenging problems before receiving any specific instruction, while students often fail to produce satisfactory solutions (hence failure happens). The results also illustrated the high level of the experimental group, studied by PF, and that improvement is particularly significant among low-performing students.

Dickson et al. (2020) also used PF in a 3D printer training programme as one of the fundamental instruments in the Science, technology, engineering and mathematics (STEM) education programme for middle school students. In this study, students and the teacher had no prior knowledge on this topic that led to many failures, and thus such failure was not designed into the lesson plans, but rather a product of new technology and the inexperience of teacher and students.

\subsection{Science learning through PF in a digital learning environment}

Students face difficulties while visualising and solving complex problems in chemistry. Therefore, computer-aided learning projects that create conditions for the success of PF can be utilised as it aimed at enabling students to understand abstract and often complex concepts, such as weather patterns, astronomy and basic atomic structure (Kennedy-Clark, 2009).

The PF environment can be designed using computer-aided cooperative learning groups by letting learners struggle with failure in poorly constructed and unorganised tasks that reflect a fruitful exercise towards PF (Kapur, 2010). The incorporation of new technologies may provide sufficient incentive for students to participate in learning without feeling frustrated even with the use of PF activities (Dickson et al., 2020). In this regard, Song's (2018) study asserted the improvement of the cooperative problemsolving competence among elementary school students in project-based learning using PF. The results showed that the experimental group gained a deeper understanding of the conceptual knowledge and the quality of problem-solving collaboratively. They were also more positive in meeting challenges in their project-based learning and developing a sense of ownership of their learning compared to those in the control group.

\subsection{Stages of cognitive failure and inquiry cycle}

Brand et al. (2019) presented three stages for combining cognitive failure within the inquiry process as follows:

- Conceptualisation Stage: In this stage, students generate ideas and hypotheses about the required topic, problem or task, and in which the PF activities are designed to stimulate prior knowledge by considering this knowledge as a mechanism for learning that helps students achieve the goal.

- Investigation Stage: In this stage, data is analysed, and students first need to engage in exploration, experimentation and collecting data through conducting experiments that are based on hypotheses, controlling the strategy of variables. Students also analyse the given data sets by inventing different solutions and comparing them. This helps students to model patterns and relationships between variables. 
Ezzeldin, S. M. Y. (2022). The effect of productive failure in a digital inquiry environment on developing deep understanding and achievement of organic chemistry among secondary school students. Cypriot Journal of Educational Science. 17(2), 396-409

https://doi.org/10.18844/cjes.v17i2.6822

- Conclusion: After the previous two phases, students extract new knowledge and build mental models. In cognitive failure, knowledge gaps are bridged, and students realise the gaps that support the structure of their models.

\subsection{Deep understanding}

Deep understanding requires more than just processing knowledge, as it requires insight and capabilities that are reflected in various performances. It refers to the student's ability to critically examine new ideas and concepts, place them in his cognitive constructions and make connections between them and his prior knowledge through questions and lines of inquiry that arise from contemplation, discussion and use of ideas (Purinton \& Burke, 2020, Yu \& Lee, 2020).

Deep understanding needs knowledge enrichment as it encourages continuous growth and increases the desire to know more. It can be developed by allowing students to discuss, solve problems and rebuild the learning environment to enable ideas to be explored (Sherry, 2010). Deep understanding includes three major dimensions: cognitive, mental and emotional. The main goal of deep understanding is to employ knowledge in the future and the learners' professional life and this is what the Next Generation Science Standards seek to achieve (NGSS, 2013). In this regard, Chin and Brown (2000) argued that deep understanding includes generative thinking, the nature of interpretations, questioning and metacognitive activities. Furthermore, King (2016) explained that deep understanding incorporates students' ability to ask questions, clarify and explain away from the facts, in addition to the insistence on understanding the material and showing advanced levels of understanding.

Consequently, deep understanding includes the higher mental capabilities and skills of the learner. It has cognitive, mental and emotional dimensions. This kind of understanding has a functional significance manifested in utilising knowledge in the learner's life. This requires the student's participation in his learning because it encourages him to acquire knowledge of his own and forces him to form an organised knowledge building.

\subsection{Deep understanding and digital learning environment}

Various studies found out that deep understanding can be enhanced through students' involvement in the electronic learning environment in higher educational stages; and that podcasting is a successful tool in learning science that develops deep understanding (Grisham \& Wolsey, 2014; Purinton \& Burke, 2020).

LPI researchers have studied three large school networks, including the new technology network. They concluded that it has succeeded in implementing deep learning practices. They stated that in order to raise the level of deep understanding, project-based learning, work-study, performance assessments and demonstrating the student progress can be utilised (McLeod, 2019; Sparks, 2019). In addition, Alshdaifat et al. (2020) study provided a new framework for segmenting the fish environment in underwater videos according to a proposed model for improved identification methods. The results indicated that the proposed framework has a better performance than other modern fish splitting models, which in turn enhances a deep understanding of the marine environment.

Hence, the current study problem stimulated from the emphasis of some recent global projects that highlight the need to deepen the knowledge of learners in science, such as the Global Trends for Studying Science and Mathematics and the Next Generation Science Standards (NGSS) (Bybee, 2012, p. 544; Ford, 2015, p. 1043). Moreover, learning with PF supports the development of science aspects as they exhibit more positive attitudes while facing challenges and gain a sense of ownership of their learning, and this has been confirmed by various studies (Brand et al., 2019; Dickson et al., 2020; 
Arrington \& Xu,Arrington \& Xu, 2019; Kapur \& Bielaczyc, 2012; Kennedy-Clark studies, 2009; Song, 2018; Toh \& Kapur, 2017), but there is no Arab study - according to the researchers' knowledge - concerning the study of PF in learning science in general and chemistry in particular.

Moreover, students have difficulties in visualising and solving complex problems in chemistry. Accordingly, computer-aided learning projects can enable students to understand abstract and often complex concepts, and the use of the online multi-user virtual learning environment can support the success of PF (Kennedy-Clark, 2009). So, the PF environment can be created by e-learning (Dickson et al., 2020; Kennedy-Clark, 2009; Kapur, 2010; Song, 2018). Some studies have also focused on using PF with inquiry learning and provided teaching stages that combine both of them (Brand et al., 2019; Arrington \& Xu,Arrington \& Xu, 2019; Kapur \& Bielaczyc, 2012; Toh \& Kapur, 2017).

The world nowadays faces many risks and disasters, and science is the main gate to overcome them. Technology plays a vital role in confronting such dangers. Coronavirus disease (COVID-19) is one of the most recent risks today as it increases unexpectedly. Therefore, the current state forces the necessity of using e-learning even after the end of the pandemic (United Nations, 2020), and that motivated the researchers to conduct this study. This also supports the current study orientation towards using PF in a digital inquiry environment to develop deep understanding and achievement in secondary school chemistry learning.

\section{Methods}

\subsection{Study questions}

The problem of the present study is crystallised in the following main question:

What is the effect of using PF in a digital inquiry environment on developing deep understanding and achievement of organic chemistry among Saudi Arabian secondary school students?

This main question is divided into the following sub-questions:

1. What is the effect of using PF in a digital inquiry environment on developing deep understanding of organic chemistry among third-grade secondary school students?

2. What is the effect of using PF in a digital inquiry environment on developing achievement among third-grade secondary school students?

\subsection{Study hypotheses}

1. There are statistically significant differences at the level of $\alpha=0.05$ between the mean scores of the experimental and control groups in the deep understanding test of organic chemistry in favour of the experimental group.

2. There are statistically significant differences at the level of $\alpha=0.05$ between the mean scores of the experimental and control groups in the achievement test of organic chemistry in favour of the experimental group.

\subsection{Study limitations}

The current study is limited to:

1. A group of third-grade secondary school students at Al-Khamaseen First High School, and AlKhamaseen Second Secondary School in Wadi Al-Dawasir Governorate, Saudi Arabia. 
2. The fifth unit 'Derivatives of hydrocarbon compounds and their reactions' from the chemistry textbook 3 assigned for the high school students in natural sciences path - the courses system for the academic year 2020-2021.

3. Measuring deep understanding through three dimensions: generative thinking (fluency, flexibility, setting hypothesis and prediction in light of data), interpretation and questioning.

4. Measuring achievement according to Bloom's taxonomy of the cognitive domain including the following levels: recall, comprehension, application, analysis and synthesis.

\subsection{Study methodology}

This study utilised the descriptive and analytical approach in preparing the theoretical framework, study tools, analysis and interpretation of the results, as well as the semi-experimental approach of the experimental and control group design with the pre- and post-application, which is consistent with the nature of the current study to achieve its objectives.

\subsection{Participants}

The two schools assigned for the application were randomly selected to choose the study groups, the experimental group $(n=32)$ and the control group $(n=34)$ from the third-grade secondary school students in Wadi Al-Dawasir Governorate, Saudi Arabia.

\section{Procedures}

\subsection{Adjusting and preparing the study tools}

\subsubsection{The deep understanding test}

The objective of this test is to measure the deep understanding of organic chemistry among thirdgrade secondary school students. The total test time was 55 minutes. The initial form included 22 test items distributed into 2 types of objective questions: multiple choice to measure the skills of setting hypotheses, predicting, explaining and asking questions; and the completion items to measure the fluency and flexibility skills. The researchers conducted the pilot study for the test on a group of 21 students in the third grade of secondary school at the First Ladam Secondary School in Wadi Al-Dawasir Governorate to verify the test validity and reliability.

To verify the test face validity, the researchers presented the test to a number of jury members. The items that obtained agreements less than $90 \%$ were removed and the necessary modifications to delete or add some vocabulary in light of their opinions were conducted. The researchers also checked the construct validity by calculating internal consistency as shown in Table 1, indicating that the test has a high internal consistency.

Table 1. Correlation coefficients of deep understanding dimensions with the total score of the test

\begin{tabular}{ccc}
\hline$N$ & Dimensions & Correlation coefficients $^{+}$ \\
\hline 1 & Generative thinking & ${ }^{*} 0.82$ \\
2 & Interpretation & $*_{0.71}^{0}$
\end{tabular}

$\dagger *$ Significant at 0.05 
Ezzeldin, S. M. Y. (2022). The effect of productive failure in a digital inquiry environment on developing deep understanding and achievement of organic chemistry among secondary school students. Cypriot Journal of Educational Science. 17(2), 396-409

https://doi.org/10.18844/cjes.v17i2.6822

\section{Asking questions $\quad * 0.76$}

To verify the test reliability, Cronbach's alpha equation was used. The reliability coefficient for the test as a whole was 0.83 , indicating a high reliability coefficient. The test included in its final form 20 items distributed into deep understanding dimensions as illustrated in Table 2.

Table 2. Description of the deep thinking test specifications

\begin{tabular}{ccccc}
\hline Dimension & Items & Item numbers & Q. score & The total score \\
\hline Fluency & $15-16-17$ & 3 & 3 & 9 \\
Flexibility & $18-19-20$ & 3 & 3 & 9 \\
Setting hypotheses & $13-14$ & 2 & 1 & 2 \\
Predicting & $6-7-8$ & 3 & 1 & 3 \\
Interpretation & $1-2-3-4-5$ & 5 & 1 & 4 \\
Asking questions & $9-10-11-12$ & 4 & & 32 \\
The whole test & & 20 &
\end{tabular}

\subsubsection{The chemistry achievement test}

The objective of this test is to measure achievement according to the five levels of Bloom's taxonomy (recall, comprehension, application, analysis and synthesis) in the chemistry course 3 assigned for the secondary stage, 'the Hydrocarbon Derivatives and Interactions' unit. The total test time was 55 minutes. The items were designed in the form of multiple choices and the test included in its initial form 44 items. The pilot study was carried out for the test on a group of 23 students in the third grade of secondary school at the First Ladam Secondary School in Wadi Al-Dawasir Governorate to verify the test validity and reliability.

To verify the test face validity, the researchers presented the test to a number of jury members. The items that obtained agreements less than $90 \%$ were removed, and the necessary modifications were conducted to delete or add some vocabulary in light of their opinions. To verify the test reliability, the Kuder-Richardson reliability coefficient was used, where the value of recall was 0.84 , comprehension was 0.79 , application was 0.81 , analysis was 0.78 , synthesis was 0.82 and the whole test was 0.80 , indicating an acceptable reliability coefficient. In addition, the ease and difficulty coefficients were calculated for the test items. Three items with high ease and difficulty levels were excluded.

The test included in its final form 41 items distributed into the five levels of Bloom's taxonomy as illustrated in Table 3.

Table 3. Description of the achievement test in the 'Hydrocarbon Derivatives and Interactions' unit of the chemistry course 3 at the secondary stage specifications

\begin{tabular}{|c|c|c|c|c|c|c|c|}
\hline Objectives level & Recall & Comprehension & Application & Analysis & Synthesis & Total & Percentage \\
\hline lessons & & & & & & & \\
\hline $\begin{array}{l}\text { Alkyl Halides and } \\
\text { Aryl Halides }\end{array}$ & 4 & 2 & 2 & 2 & 2 & 12 & 29 \\
\hline Alcohols, Ethers and & 2 & 1 & 2 & & 1 & 6 & 14.6 \\
\hline
\end{tabular}


Ezzeldin, S. M. Y. (2022). The effect of productive failure in a digital inquiry environment on developing deep understanding and achievement of organic chemistry among secondary school students. Cypriot Journal of Educational Science. 17(2), 396-409 https://doi.org/10.18844/cjes.v17i2.6822

Amines

$\begin{array}{cccccccc}\text { Carbonyl compounds } & 3 & 2 & 2 & 1 & 2 & 10 & 24.5 \\ \begin{array}{c}\text { Other interactions of } \\ \text { organic compounds }\end{array} & 2 & 1 & 1 & 4 & 2 & 10 & 24.5 \\ \text { Polymers } & 1 & 1 & & 1 & & 3 & 7.4 \\ \text { Total } & 12 & 7 & 7 & 8 & 7 & 41 & 100 \\ \text { Percentage } & 29 & 17 & 17 & 20 & 17 & & 100\end{array}$

\subsection{Application mechanisms}

The teacher's guide and students' book for applying PF in the digital inquiry environment were prepared for the assigned unit. The teacher's guide included an introduction, general directions, learning procedures for the product failure and deep understanding, a background about this method, a time plan for teaching and lesson plans according to the PF method. The students' book included an introduction, general directions for students, a summary of learning with PF and deep understanding, the classroom lessons using PF and inquiry worksheet, including poorly constructed tasks and wellconstructed tasks.

The study utilised the Microsoft Teams platform in teaching the assigned unit and in applying the study tools, as it is an approved platform by the Ministry of Education in the Kingdom of Saudi Arabia. Mainly, it has many advantages as it has a complete security system because it requires logging in using a Microsoft account approved by the ministry for both teachers and students. It has the possibilities for screen sharing, conducting discussions in the chat, exchanging conversations through voice sharing, sharing the whiteboard and organising posts by raising hands.

Inquiry tasks were presented sequentially by providing poorly constructed tasks, followed by wellconstructed ones. The students have to solve problems that require them to use more advanced concepts individually. The three basic stages (conceptualisation, investigation and conclusion) were also applied. The first part of the class time (about 25 minutes) was assigned to students' activities in solving inquiry tasks in the visualisation and investigation stages. These activities were designed at the higher cognitive levels to develop deep understanding, comprising data interpretation and prediction. This was followed by the conclusion stage where students' answers were collected and immediate formative observations were provided and this took about 15 minutes, while the remaining lesson time (about 5 minutes) was to close the lesson.

\section{Results}

\subsection{The first hypothesis result}

'There are statistically significant differences at the level of $\alpha=0.05$ between the mean scores of the experimental and the control groups in the deep understanding test of organic chemistry in favour of the experimental group': to verify the validity of this hypothesis, $t$-test was used as shown in Table 4. 
Ezzeldin, S. M. Y. (2022). The effect of productive failure in a digital inquiry environment on developing deep understanding and achievement of organic chemistry among secondary school students. Cypriot Journal of Educational Science. 17(2), 396-409

https://doi.org/10.18844/cjes.v17i2.6822

Table 4. Results of $t$-test for the significance of the differences between the control and experimental groups in the deep understanding test in organic chemistry

\begin{tabular}{|c|c|c|c|c|c|c|c|c|}
\hline \multirow[t]{2}{*}{ Item } & \multirow[t]{2}{*}{$\begin{array}{c}\text { The } \\
\text { highest } \\
\text { degree }\end{array}$} & \multicolumn{2}{|c|}{$\begin{array}{c}\text { The } \\
\text { experimental } \\
\text { group }\end{array}$} & \multicolumn{2}{|c|}{$\begin{array}{l}\text { The control } \\
\text { group }\end{array}$} & \multirow[t]{2}{*}{$t$ value $^{\ddagger}$} & \multirow[t]{2}{*}{$\begin{array}{c}\text { Significance } \\
\text { level }\end{array}$} & \multirow[t]{2}{*}{$\eta^{2}$} \\
\hline & & Mean & St. dv & Mean & St. dv & & & \\
\hline Fluency & 9 & 6.81 & 0.95 & 3.29 & 0.95 & $* 12.82$ & & 0.79 \\
\hline Flexibility & 9 & 6.22 & 1.0 & 3.13 & 0.99 & $* 11.0$ & & 0.73 \\
\hline $\begin{array}{c}\text { Setting } \\
\text { hypotheses }\end{array}$ & 2 & 1.7 & 0.48 & 0.83 & 0.70 & $* 4.75$ & 0.05 & 0.34 \\
\hline Predicting & 3 & 2.23 & 0.69 & 1.21 & 0.84 & $* 4.52$ & & 0.32 \\
\hline Interpreting & 5 & 4.0 & 0.72 & 2.33 & 1.10 & *5.89 & & 0.44 \\
\hline $\begin{array}{c}\text { Asking } \\
\text { questions }\end{array}$ & 4 & 3.27 & 0.94 & 2.63 & 2.42 & 1.17 & & 0.03 \\
\hline The whole test & 32 & 24.18 & 1.74 & 13.42 & 3.75 & $* 12.3$ & & 0.78 \\
\hline
\end{tabular}

Table 4 reveals that there are statistically significant differences between the experimental and control groups in fluency, flexibility, setting hypothesis, predicting, interpreting, asking questions and deep understanding test as a whole in favour of the experimental group.

\subsection{The second hypothesis result}

'There are statistically significant differences at the level of $(\alpha=0.05)$ between the mean scores of the experimental and the control groups in the achievement test of organic chemistry in favour of the experimental group': to verify the validity of this hypothesis, $t$-test was used as shown in Table 5.

Table 5. Results of the ' $t$ '-test for the significance of the differences between the control and experimental groups in the achievement test of organic chemistry

\begin{tabular}{|c|c|c|c|c|c|c|c|c|}
\hline \multirow[t]{2}{*}{ Item } & \multirow[t]{2}{*}{$\begin{array}{c}\text { The } \\
\text { highest } \\
\text { degree }\end{array}$} & \multicolumn{2}{|c|}{$\begin{array}{c}\text { The } \\
\text { experimental } \\
\text { group }\end{array}$} & \multicolumn{2}{|c|}{$\begin{array}{l}\text { The control } \\
\text { group }\end{array}$} & \multirow[t]{2}{*}{$\begin{array}{c}t- \\
\text { value }^{\S}\end{array}$} & \multirow[t]{2}{*}{$\begin{array}{c}\text { Significance } \\
\text { level }\end{array}$} & \multirow[t]{2}{*}{$\eta^{2}$} \\
\hline & & Mean & St. dv & Mean & St. dv & & & \\
\hline Recall & 12 & 9.32 & 1.64 & 7.79 & 2.60 & 2.35 & & 0.112 \\
\hline Comprehension & 7 & 5.5 & 1.52 & 4.58 & 1.52 & 2.28 & & 0.104 \\
\hline Application & 7 & 5.86 & 0.94 & 2.95 & 0.96 & *10.38 & & 0.710 \\
\hline
\end{tabular}

* Significant at 0.05

$\S *$ Significant at 0.05 
Ezzeldin, S. M. Y. (2022). The effect of productive failure in a digital inquiry environment on developing deep understanding and achievement of organic chemistry among secondary school students. Cypriot Journal of Educational Science. 17(2), 396-409 https://doi.org/10.18844/cjes.v17i2.6822

\begin{tabular}{c|cccccccc} 
Analysis & 8 & 6.45 & 1.01 & 3.67 & 1.57 & $* 7.2$ & & 0.531 \\
Synthesis & 7 & 6.1 & 0.87 & 2.5 & 0.66 & $* 16.8$ & 0.05 & 0.855 \\
The whole test & 41 & 33.23 & 2.86 & 21.46 & 3.10 & $* 13.38$ & & 0.801
\end{tabular}

Table 5 reveals that there are no statistically significant differences between the experimental and control groups in the recall and comprehension levels, while there were statistically significant differences between the experimental and control groups in the application, analysis, synthesis and the whole achievement test in favour of the experimental group.

\section{Discussion}

The importance of PF and the necessity to utilise technology in education have been increasingly realised in the literature. Consequently, it is essential to understand the effect of using them in science education. First, the results demonstrated that there were statistically significant differences between the experimental and control groups in fluency, flexibility, setting hypothesis, prediction, interpretation, questioning and deep understanding test as a whole in favour of the experimental group. This result is consistent with the studies of Purinton and Burke (2020) and Grisham and Wolsey (2014) on the effectiveness of using the digital learning environment in developing deep understanding dimensions. These results are also in agreement with the studies of Kennedy-Clark (2009), Kapur (2010), Song (2018) and Dickson et al. (2020) on the effectiveness of using PF in the e-learning environment to develop students' thinking skills. On the contrary, the results differ from the study of Kapur (2010) who concluded that PF has effectiveness when working in groups, while the current study applied PF individually.

This result may be explained by the idea that PF depends on the learners' struggle to find out solutions to problems before not after training on them about a specific concept and understanding the obstacles presented. Basically, PF is one of the highest levels of active learning and interaction and this was achieved in all inquiry tasks that were presented to students according to PF procedures in this study. In addition, the inquiry that included poorly constructed tasks were new but not frustrated that might have an impact on developing their deep understanding. Consequently, in the case of PF, students concluded with new knowledge from carrying out such inquiry that increases the chances of success in each attempt. Hence, the more procedures that are taken, the deeper the knowledge will be, and the more successful the student will be through an increasing failure rate.

The stages of PF worked on developing the skills of fluency, as the effect size was 0.79 through training on the inquiry tasks that require many paths and methods to answer by developing the largest possible number of structural formulas for different organic compounds, such as alcohols, acids, aldehydes and ketones, which were presented in every lesson. Furthermore, the increasing effect size of flexibility skills (0.73) can also be explained by the inquiry questions that require moving from one category to another such as presenting the inquiry of carbonyl compounds and the possibility of changing the associated atoms, so that the composition and properties of the organic matter completely change.

The moderate effect size of setting hypotheses skills (0.34) and interpretation skills (0.44) may be due to the interest of the students' textbook to present some questions at the end of each unit concerning such skills. This also made the control group trained on them. However, the current study presented further inquiries that supported both skills such as the inquiry of alcohols temperature, predicting the differences between alcohols boiling points, aldehydes and acids which contributed to such moderate development. In addition, some inquiries also concerned with the development of interpretation skills 
Ezzeldin, S. M. Y. (2022). The effect of productive failure in a digital inquiry environment on developing deep understanding and achievement of organic chemistry among secondary school students. Cypriot Journal of Educational Science. 17(2), 396-409

https://doi.org/10.18844/cjes.v17i2.6822

such as interpreting weak acidity of carboxylic acids and significant volatilisation of ethers. The weak effect value of asking questions skills (0.03) may be interpreted according to the fact that this skill is one of the skills which the standardised tests for both groups focused on.

The effect size of deep understanding as a whole (0.78), which was a high value, can be explained by the fact that PF achieves a positive impact in promoting the acquisition of conceptual knowledge through understanding the basic principles and structures of the learning field. Also, inquiries were presented in a poorly constructed form with no direct instructions on how to solve the problems, contributing to students' engagement in remedial treatment using their prior knowledge to fill in the conceptual gaps.

Moreover, providing the opportunity for students to fail in the first stage, namely investigation, may have contributed to the acquisition of negative knowledge (Loibl \& Leuders, 2019), through which learners reflect on their mistakes and this, in turn, prevents them from committing similar errors again. In this stage, data analysis and interpretation helps them to model the patterns and relationships between different concepts of organic compounds and their interactions.

Regarding the effect of the digital learning environment (Microsoft Teams platform), it was evident that it supported students' participants through writing in chat, sharing the voice and writing on the whiteboard which affected students' deep understanding. The ease with which the teacher shared the screen and students' participation in inquiry also helped in presenting the abstract and complex organic chemistry concepts. In the second PF stage, the conceptualisation stage, where the students generate ideas and hypotheses about the required task, prior knowledge was activated and included in the students' book, and attention was given to it to be organised into the students' cognitive structure, which assisted them to achieve the objective.

Second, the results demonstrated that there are statistically significant differences between the experimental and control groups in the achievement test of organic chemistry in favour of the experimental group. This result is consistent with the studies of Kennedy-Clark (2009), Kapur (2010), Song (2018) and Dickson et al. (2020) regarding the effectiveness of using PF in the e-learning environment in developing achievement in general and higher levels of achievement in particular.

The absence of the statistically significant differences between the experimental and control group in the level of recalling and comprehension and the low effect size of them (0.112 and 0.104$)$ may be explained due to the fact that PF and the control group teaching method contributed to the development of their levels. Consequently, the differences between the averages of both groups were small concerning remembering and understanding levels.

Regarding the application level, the effect size was 0.710 and this is due to providing students with many opportunities to apply what they learned in well-constructed tasks in the visualisation stage by presenting examples of different organic compounds and students were asked to name them in every lesson such as naming alkyl halides, aryl halides, alcohols, esters, amines and carboxylic acids.

The value of the analysis level effect size (0.531) that was high may have contributed to the analysis of the given and missing data and information in the investigation and visualisation stages such as the differences between aldehydes and ketones, the differences between the carbonyl group compounds and the differences between the deletion reactions: addition, condensation, hybridisation, oxidation and reduction.

The value of the comprehension level effect size was 0.855 , which is high, and may be mainly due to the conclusion stage where the students extract new knowledge, build mental models and fill in the knowledge gaps. In addition, each inquiry ends with a request for a summary of what has been reached about the composition of the organic compounds under consideration and their general formula, 
presenting examples, mentioning some of their physical properties and stating the difference between them and other organic compounds.

The value of the effect size of the test as a whole was 0.801 , which is high, and may be attributed to all the above-mentioned reasons and to the fact that the inquiry produced by the Microsoft Teams platform allows students to upload files that they participate in on the chat, as well as attach what was extracted in the form of assignments on the platform, which may have supported the achievement in organic chemistry.

\section{Conclusion}

The main purpose of this study was to measures the effect of using PF in a digital inquiry environment on developing the deep understanding and achievement of organic chemistry among Saudi Arabian secondary school students. This topic has not been previously studied in the Arab context, and despite the existence of several international studies that focused on such variables and providing the effectiveness of the PF method, research in this area is spare. The results of this study are expected to represent a relevant contribution to understand this issue and contribute to the development of other studies in this field. The current study drives its significance from presenting a teacher's guide that includes the procedural application for the PF in a digital inquiry environment in organic chemistry, the preparation of the deep understanding and the achievement test of organic chemistry; directing the attention of chemistry curriculum planners and developers to the need to adopt PF in the digital inquiry environment to develop deep understanding and achievement in other disciplines and educational stages.

Clarifying the effectiveness of PF in the digital inquiry context was extremely important to be implemented and improved into different educational stages to prepare students for modern requirements. In light of the results presented and their interpretation, the study recommends the following: high school chemistry teachers have to pay attention to PF to develop a deep understanding and achievement in organic chemistry; high school chemistry teachers have to familiarise with the goal orientation adopted by students and how to identify it, because this helps them support the goal orientation that is most useful and important in learning chemistry; professional development stakeholders should hold training courses for in-service science teachers and their branches in the various academic stages to train them on the use of PF in teaching science in general and in chemistry in particular to develop deep understanding and achievement among students; and finally, programmes for preparing science teachers in general and chemistry in particular should include PF and its related concepts, as well as the goal orientation of the decisions of teaching methods.

\section{Acknowledgement}

The authors would like to express their sincere gratitude to the research participants.

\section{References}

Alshdaifat, F., Talib, A., \& Osman, A. (2020). Improved deep learning framework for fish segmentation in underwater videos. Ecological Informatics, 59, 1-11.

Arrington L., Xu X. (2019) Press Play! How Immersive Environments Support Problem-Solving Skills and Productive Failure. In: Ifenthaler D., Kim Y. (eds) Game-Based Assessment Revisited. Advances in Game-Based Learning. 
Ezzeldin, S. M. Y. (2022). The effect of productive failure in a digital inquiry environment on developing deep understanding and achievement of organic chemistry among secondary school students. Cypriot Journal of Educational Science. 17(2), 396-409

https://doi.org/10.18844/cjes.v17i2.6822

Springer, (pp. 121-139). Springer. https://doi.org/10.1007/978-3-030-15569-8 7Brand C., Massey-Allard, J., Perez S., Rummel N., \& Roll I (2019). What inquiry with virtual labs can learn from productive failure: $A$ theory-driven study of students' reflections? In S. Isotani, E. Millan, A. Ogan, P. Hastings, B. McLaren, \& R. Luckin (Eds.), Artificial intelligence in education. AIED 2019. Lecture Notes in Computer Science, 11626. https://doi.org/10.1007/978-3-030-23207-8 6

Bybee, R. (2012). The next generation science standards: Implications for biology education. The American Biology Teacher, 74(8), 542-549. https://doi.org/10.1525/abt.2012.74.8.3

Chin, C., \& Brown, D. (2000). Learning in Science a Comparison of Deep surface Approaches. Journal of research in science teaching, 37 (2), 109-138. https://doi.org/ 10.1002/(SICI)1098-2736(200002)37:2<109::AIDTEA3>3.0.CO;2-7

Chowrira, S., Smith, K., Dubois, P., \& Ido, R. (2019). DIY productive failure: Boosting performance in a large undergraduate biology course. NPJ Science of Learning, 4(1), 1-8. https://doi.org/ 10.1038/s41539-019-0040$\underline{6}$

Dickson, B., Weber, J., \& Boyd, T. (2020). The role of productive failure in 3D printing in a middle school setting. International Journal of Technology and Design Education, 9(33), 149-159. https://doi.org/10.1007/s10798$\underline{020-09568-z}$

Ford, M. (2015). Educational implications of choosing "Practice" to describe science in the next generation science standards. Science Education, 99(6), 1041-1048. https://doi.org/10.1002/sce.21188

Grisham, D., \& Wolsey, T. (2014). Podcasting for deeper science learning. California Reader, 47(3), 18-26.

International Association for the Evaluation of Educational Achievement. (2015, October). Socioeconomically disadvantaged students who are academically successful: Examining academic resilience cross-nationally. https://www.iea.nl/fileadmin/user_upload/Policy Briefs/IEA_policy_brief Mar2015.pdf

Kapur, M. (2010). Productive failure in mathematical problem solving. Instructional Science, 38(6), 523-550. https://doi.org/10.1007/s11251-009-9093-x

Kapur, M. (2015). The preparatory effects of problem solving versus problem posing on learning from instruction. Learning and Instruction, 39, 23-31. https://doi.org/10.1016/i.learninstruc.2015.05.004

Kapur, M., \& Bielaczyc, K. (2012). Designing for productive failure. Journal of the Learning Sciences, 21(1), 45-83. https://doi.org/10.1080/10508406.2011.591717

Kennedy-Clark, S. (2009) Designing failure to encourage success: Productive failure in a multi-user virtual environment to solve complex problems. In U. Cress, V. Dimitrova, \& M. Specht (Eds.), Learning in the synergy of multiple disciplines. EC-TEL 2009. Lecture Notes in Computer Science, Vol. 5794. Springer, Berlin, Heidelberg. https://doi.org/10.1007/978-3-642-04636-0 56

King, C. (2016). Fostering deep understanding through the use of geoscience investigations, models and thought experiments: The earth science education unit and Earth learning idea experiences. In Vasconcelos C. (eds), Geoscience Education (pp. 3-23). Springer. https://doi.org/10.1007/978-3-319-43319-6 1

Loibl, K., \& Leuders, T. (2019). How to make failure productive: Fostering learning from errors through elaboration prompts. Learning and Instruction, 62(1), 1-10. https://doi.org/10.1016/j.learninstruc.2019.03.002

McFarland, M. \& Moulds, P. (2007). Leading, learning and teaching for understanding. Journal of Principal Leadership, 7(9), 48-51.

McLeod, S. (2019). Redesigning instruction for deeper learning and student engagement. International Educator, 33(3), 15. Corpus ID: 16803110

Next Generation Science Standards (NGSS). (2013). APPENDIX F - Science and Engineering Practices in the NGSS.113. www.nextgenscience.org 
Ezzeldin, S. M. Y. (2022). The effect of productive failure in a digital inquiry environment on developing deep understanding and achievement of organic chemistry among secondary school students. Cypriot Journal of Educational Science. 17(2), 396-409 https://doi.org/10.18844/cjes.v17i2.6822

Purinton, E., \& Burke, M. (2020). Engaging online students: Using a multisensory exercise for deeper, active learning. Marketing Education Review, 30(1), 29-42. https://doi.org/10.1080/10528008.2019.1677478

Sherry, B. (2010). What is deep understanding? Learning zone mindfully thinking about learning. https://bsherry.wordpress.com/2010/02/28/what-is-deep-understanding/

Song, Y. (2018). Improving primary students' collaborative problem-solving competency in project-based science learning with productive failure instructional design in a seamless learning environment. Educational Technology Research and Development, 66, 979-1008. https://doi.org/10.1007/s11423-018-9600-3

Sparks, S. (2019). Networks help expand 'Deeper Learning' in schools. Education Week, 39(11), 6-10.

Steenhof, N., Woods, N., Van Gerven, P., \& Mylopoulos, M. (2019). Productive failure as an instructional approach to promote future learning. Advances in Health Sciences Education: Theory and Practice, 24(4), 739-749. https://doi.org/10.1007/s10459-019-09895-4

Sternberg, R. (1999). Cognitive psychology. Harcourt Brace College Publishers.

Toh, P., \& Kapur, M (2017). Is having more prerequisite knowledge better for learning from productive failure? Instructional Science, 45, 377-394. https://doi.org/10.1007/s11251-016-9402-0

United Nations (2020). Education during the COVID-19 pandemic and beyond. https://www.un.org/sites/un2.un.org/files/policy brief - education during covid-

19 and beyond arabic.pdf

Yu, C. \& Lee, H. (2020). Creating change to improve science and mathematics education: Lessons from Hong Kong. Springer Nature. ISBN 978-981-15-3155-2 ISBN 978-981-15-3156-9 (eBook). https://doi.org/10.1007/978-981$\underline{15-3156-9}$ 